\title{
When People with Opioid-Induced Constipation Speak: A Patient Survey
}

Robert S. Epstein · J. Russell Teagarden · Ali Cimen •

Mark Sostek (D) Tehseen Salimi

Received: October 19, 2016 / Published online: February 8, 2017

(c) The Author(s) 2017. This article is published with open access at Springerlink.com

\begin{abstract}
Introduction: Opioid-induced constipation (OIC) is a common consequence of opioid use for chronic pain. OIC creates problems for patients independent of their pain syndromes, in addition to threatening pain treatment effectiveness. Healthcare practitioners need to be alert to how patients talk about OIC so that it is not missed. Using a survey mechanism, we sought patient expressions of the personal impact OIC imposes on how they are able to live their lives and on meanings that symptom relief would produce.

Methods: We used an online survey asking adults with OIC about quality of life implications of OIC and focused on open-ended text responses to questions about personal impacts of straining and meanings attached to OIC symptom relief. Participants were from the US, Canada, UK, Germany, Sweden, and Norway.
\end{abstract}

Enhanced content To view enhanced content for this article go to www.medengine.com/Redeem/ 4487F0601B744FED.

R. S. Epstein · J. R. Teagarden $(\bowtie)$

Epstein Health, Woodcliff Lake, NJ, USA

e-mail: rteagarden@epsteinhealth.com

A. Cimen

AstraZeneca, Cambridge, UK

M. Sostek · T. Salimi

AstraZeneca, Gaitherburg, MD, USA
Results: A survey of 513 people with OIC produced 280 text responses concerning the impacts of straining on quality of life and 469 text responses on the meaning OIC symptom relief would confer. Text responses about the quality of life impacts of straining often included explicit descriptions conveying physical, psychological, or practical problems. Text responses about the meaning conferred from OIC symptom relief primarily concentrated around freedom from the constraints that OIC can impose.

Conclusions: Patients are willing and able to comment on the problems OIC cause them, using a variety of terms and phrases. Their comments concerning impacts on their lives will often refer to physical consequences, psychological effects, or practical implications. These insights provide healthcare practitioners guidance on how to engage patients about OIC.

Keywords: Gastroenterology; Opioid-induced constipation; Pain; Patient survey; Quality of life

\section{INTRODUCTION}

Elizabeth Scarry famously framed a predicament many people with chronic pain find themselves in as, "to have great pain is to have certainty; to hear that another person has pain is to have doubt" [1]. People with chronic pain are thus 
often haunted by the prospect that those who they depend upon for treatment, support, and empathy may not believe them. Their predicament extends further when they need these others-including healthcare practitioners-to believe that the drugs they take for pain also cause them particular problems, such as opioid-induced constipation (OIC).

OIC is characterized by a change from baseline bowel habits when initiating opioid therapy, and specifically comprises: reduced bowel movement frequency; development or worsening of straining to pass bowel movements; and a sense of incomplete rectal evacuation or harder stool consistency [2]. Incidence rates have ranged from $41 \%$ across clinical trials involving noncancer patients [3] to $62 \%$ in a survey of patients across several cancer clinics [4], and to $86 \%$ of cancer and noncancer patients drawn from the National Health and Wellness Survey [5]. Many efforts have been directed at discerning the effects and impact of OIC. We know OIC causes physical problems [4-7], along with anxiety, distress, and fear among other psychological effects $[4,7,8]$. We know it interferes with activities of daily living, diminishes quality of life, and intrudes upon family interactions [4-6]. We even know that OIC often upends the efforts of patients to comply with pain management treatment plans, and results in higher utilization of healthcare resources [3-9]. Not known nearly as well is how patients verbally express the personal effects and impacts of OIC. Knowing how patients verbalize OIC problems as they affect their lives could help clinicians identify new cases, educate those initiating opioid therapy, and assess cases already under treatment.

We sought verbatim responses from patients with OIC about how the difficulties of bowel movements affect their quality of life and about the importance they attach to experiencing complete bowel movements. These verbatim responses were recorded as part of a larger survey concerned with the OIC symptoms patients would most like addressed and the minimal clinically important difference in treating this condition. The findings of that aspect of the survey have since been published [10]. We report here the findings from the verbatim responses collected from the survey.

\section{METHODS}

\section{Survey Population}

We targeted a total survey population of 500 people with OIC from the US, Canada, UK, Germany, Sweden, and Norway. Survey participants were drawn from an established, online database of over 800,000 people who have agreed to receive offers to participate in online surveys. Those who agree to participate are engaged through a patented, secured, proprietary system, which is ISO 26362 certified (HealthiVibe, Arlington, VA, USA).

Potential participants were screened by e-mail. Inclusion criteria included the following: minimum age of 18 years; self-report chronic, noncancer pain; manage chronic pain with opioid medications; self-report at least two active OIC symptoms, which could encompass infrequent bowel movements, required straining, hard stools, and incomplete bowel emptying; and can participate in the language where the survey was administered, and willingness to participate. Participants could be on weak opioids (i.e., tramadol, codeine, dihydrocodeine, hydrocodone) or strong opioids (i.e., oxycodone, morphine, fentanyl, hydromorphone, methadone). Potential participants were told that the survey would take $12-15 \mathrm{~min}$ to complete.

\section{Survey Questions}

Participants were asked to provide text responses to two questions. The first question was (for participants who had earlier said straining did affect their quality of life):

Please describe how straining to make a bowel movement ("rectal straining") affects your quality of life?

The second question asking for a text response was: 
In your opinion, what does it mean to have a complete bowel movement?

Text responses collected for the two questions were first separated into those that were discernable and those not discernable. Responses that were not discernable were those that gave no detail on the effects or impacts OIC caused. These responses often took the forms of no responses at all, uncertainty about the question (e.g., "no idea"), or just unassociated adjectives (e.g., "bad," difficult"). Discernable responses were then assessed for evident themes and impacts as they were read and judged, and not as they would be if they were to be classified into pre-determined categories derived from a validated instrument.

\section{Compliance with Ethics Guidelines}

This article does not contain any new studies with human or animal subjects performed by any of the authors.

\section{RESULTS}

Five hundred and thirteen participants completed the survey between 13 and 27 May 2014 . The average respondent age was 46 years (STD $13), 55 \%$ of them were female, $88 \%$ were Caucasian, and over $92 \%$ were at least high school graduates. Across the respondent population, $22 \%$ were from the US, $22 \%$ from Canada, 23\% were from the UK, 19\% from Germany, 10\% from Sweden, and $4 \%$ from Norway.

In terms of ratings of their general health, participants typically reported good or fair health and had been experiencing pain for over 10 years (Table 1 ). On a scale of $0-10$, with 10 representing the worst pain, participants rated their average pain as 6.7 during the 7 days preceding the survey. Some $58 \%$ of participants were using strong opioids, most commonly for back or joint pain.

The text responses to the first question about the impact of straining on quality of life were solicited as a way to expand on the binary question asked, "Does straining to have a bowel movement ('rectal straining') affect your quality
Table 1 Health and pain characteristics of survey participants

\begin{tabular}{|c|c|}
\hline Wellness or pain characteristic & $\begin{array}{l}\text { Participants } \\
(\% \text { or } S D)^{\mathrm{a}} \\
n=513\end{array}$ \\
\hline \multicolumn{2}{|l|}{ Self health rating } \\
\hline Excellent & $13(2.5 \%)$ \\
\hline Very good & $46(8.9 \%)$ \\
\hline Good & $185(36.1 \%)$ \\
\hline Fair & $185(36.1 \%)$ \\
\hline Poor & $84(16.4 \%)$ \\
\hline \multicolumn{2}{|l|}{ Reason for pain ${ }^{\mathrm{b}}$} \\
\hline Back pain & $409(79.7 \%)$ \\
\hline Joint pain & $358(69.8 \%)$ \\
\hline Headache & $254(49.5 \%)$ \\
\hline Osteoarthritis & $145(28.3 \%)$ \\
\hline Nerve damage & $144(28.1 \%)$ \\
\hline Rheumatoid arthritis & $119(23.2 \%)$ \\
\hline Pain syndrome & $106(20.7 \%)$ \\
\hline Fibromyalgia & $104(20.3 \%)$ \\
\hline Average pain rating in last 7 days $(0-10)^{c}$ & $6.7(S D 1.6)$ \\
\hline Duration of pain (years) & $10.6(\mathrm{SD} 9.5)$ \\
\hline \multicolumn{2}{|l|}{ Opioid medication strength } \\
\hline Strong & $298(58.1 \%)$ \\
\hline Weak & $215(41.9 \%)$ \\
\hline
\end{tabular}

of life?" Two hundred and ninety-eight (58\%) of the respondents said "yes," of whom 291 (98\%) provided 278 discernable text responses.

Many respondent comments referred to specific physical effects straining caused them. These responses indicated how OIC problems can be communicated through descriptions of pain, but also through problems with sitting, walking, exhaustion, and the need for invasive 
procedures. Some illustrative verbatim responses collected include the following:

I am in pain when I have to strain to have a bowel movement, and when it's over I am hot and tired, don't want to do anything except rest.

It causes intense pain that leaves me feeling unable to walk.

I bleed a lot and leakage is a problem for me and intense pain has me in tears, it's difficult to sit on any hard surface.

It makes my rectum sore so it's hard to sit and it affects my lower back so badly sometimes I can barely move. I have had to have a major prolapse surgery.

Participant text responses also produced some keys to how they express the psychological impacts of straining due to OIC. They refer to anxiety, depression, fear, and obsessions among other concerns, and as illustrated by the following comments:

Anticipation of having a difficult time with bowel movements causes anxiety. The strain and hard stools cause regular flare-ups of hemorrhoids and I worry about the bleeding.

It makes me depressed and useless.

It's gotten to the point where it's developed into a permanent, subliminal fear of bowel movements.

Can't concentrate on anything apart from my health.

I am always thinking about it and how to go to the toilet and I am on and off the toilet straining to go. And I look pregnant all the time so I am self-conscious all the time.

Practical consequences of straining from OIC were frequently the primary emphasis in comments. These consequences encompassed problems with being able to perform activities of daily living, conduct a normal social life, and undertake work duties. The following comments are representative:

I spend hours in the washroom, I cry, because it is too painful and I can't do anything.
It makes me hurt and not want to move or go anywhere. It also makes me worried that when I go somewhere it's going to happen when I'm out and if I don't leave my house in pain I'll end up in pain while I'm out and have to leave.

I no longer have any more time to go out since I'm waiting to have a bowel movement. Often, I don't have any more time to do anything because of stomach pain because I can't go to the bathroom.

I take too much time attempting to have a bowel movement and I end up having to rush and am late for appointments, work, etc. Additionally, the straining causes lingering discomfort that negatively affects my sex life.

Disruptive at work and often uncomfortable when among family or friends. All activities and plans have to be planned accordingly, so it takes away a lot of spontaneity.

The second question seeking open-ended text responses, which concerned what it would mean to respondents to have complete bowel movements, did not limit input based on answers to an antecedent question. Therefore, more responses were collected for this question. Four hundred and eighty-six participants (95\%) provided 469 discernable responses. The general theme coming through the verbatim responses about what meaning they would attach to OIC resolution had mostly to do with relief and freedom to go about their lives as they would like and as they need, not to any direct effects on their bowels. These responses could have been conditioned by other questions in the survey. Indeed, they further linked relief and freedom to many of the physical, psychological, and practical problems they identified in the first question asking for text responses. Representative responses include the following:

It would be a huge relief for me, instead of always having to suffer over and over.

It means the freedom from worry and confident that my bowels are regular and I am pain free.

It would give me freedom to go out and live the way most people do.

Bliss, no straining no pain quick and easy. 
Everything - I would feel so much better and enjoy my life so much more!

It would make my life a lot easier.

More quality of life and relief.

It is natural and I don't need to concentrate on the problem.

\section{DISCUSSION}

Chronic pain is hard enough to bear for many people that any added intolerable effects from opioids can make their situations altogether unbearable. OIC is one of those effects that can make pain and its treatment unbearable, and as one respondent said in our survey, "your life becomes very limited". As serious as OIC is, it still remains a step yet removed from the primary problem. If there can be doubt about someone else's pain, there can be doubt about someone else's OIC. However, people with OIC can and will describe the problems OIC causenearly every one of the respondents provided text comments. Nevertheless, they need to have the courage to share and the environment to be heard. Their healthcare providers need to be alert and attentive to how these problems are expressed and how they link to quality of life. This survey provides important insights concerning how patients express the impacts of OIC, which often have elements pertaining to physical consequences, psychological effects, and practical implications. These insights can help healthcare practitioners enter into discussions with patients about OIC, and could facilitate the patient-physician communication needed to get solutions [11].

Whitman et al. found that social media is a rich source for patient experience with OIC [12]. They evaluated 88,586 Twitter posts ("tweets") and 7604 electronic forum posts from three health-related websites for text related to opioid-induced gastrointestinal problems, including OIC. No less than $42 \%$ of the posts concerned OIC. The investigators discerned three particular themes running through the posts: "doctor-patient communication," "balancing opioids and side effects," and "constipation-alleviating methods." Our survey touched on the balancing of opioids and constipation-alleviating methods, in that questions were asked about how the bowel movement process in OIC affects quality of life and what meanings people with OIC would attach to achieving effective OIC relief. Respondents often lamented the time lost to OIC, making rapid relief important to them.

Our survey, along with the Whitman et al. analysis, offers several paths for physicians to initiate discussions with patients to discover when OIC is a problem and achieve a greater understanding about the particular problem a patient is experiencing. Based on themes we saw emerge across participant verbatim comments, patients can express OIC with an emphasis on the physical, psychological, or practical problems it causes. Physicians should not wait for patients to initiate discussions about OIC because they are often hesitant to discuss it. Coyne et al., for example, reported that over a third of patients do not bring the subject up with their physicians [6], while Rauck and colleagues noted that $20 \%$ of OIC sufferers felt uncomfortable talking about their condition with a healthcare provider; most commonly because of embarrassment [13]. Despite this reluctance at times to bring the matter up, patients with OIC have been shown to be capable of comprehending inquiries about OIC symptoms and effects [7]. And, our survey indicates that, when given the opportunity, patients will respond to inquiries about OIC, as nearly all participants who said OIC affects their quality of life (98\%) provided text responses about how their lives are affected, and nearly all survey respondents (95\%) provided text responses on what OIC relief would mean to them.

Our survey found text responses reporting anxiety and depression as a consequence of OIC. These findings add to those of Rauck and colleagues, who noted high rates of depression, reports of low self-esteem, and feelings of social isolation among their OIC survey participants [13].

Our evaluations of the text responses we collected suggest that the problems patients have with OIC can refer to explicit physical, psychological, and practical impacts. These 
evaluations derived from a subjective analysis to ascertain general themes rather than posing validated questions to participants. We wanted to react to the way patients are likely to express to their experiences to healthcare professionals based on their vernacular. The judgments we applied to discern themes from comments are subject to more error than had we derived the themes through a validated instrument and had we included questions beyond straining and complete bowel movements to capture the broader OIC symptom complex. But, these themes should still be relevant to healthcare professionals who have to resolve OIC problems as patients express them in clinical and social settings.

However, taking this approach creates limitations in the degree to which other researchers could replicate the findings. Other limitations concern the degree to which the findings can be considered generalizable to all people experiencing OIC, because the survey respondents represent a group that is engaged enough to take part in an online survey. They were screened for certain inclusion and exclusion criteria, but they still represented a subset of people with OIC. Without a formal categorization theme, we did not tabulate the number of responses linked to physical, psychological, or practical impacts, and, therefore, no generalizations can be made about how often patients are experience these types of consequences. The findings should be considered along with findings from other populations such as those drawn from social media sources [12], and from those interviewed in clinical settings [4]. Findings from these different patient subgroups show that problems related to OIC are not isolated to patient subgroups based on where they are situated when asked about OIC.

\section{CONCLUSION}

The patient verbatim comments gathered from our survey emphasize that OIC affects the way patients can live their lives and can be expressed as physical consequences, psychological effects, and practical implications. The verbatim comments our survey and others have gathered should leave no doubt that OIC is real and adds its own element of suffering to those who are in pain and taking opioids. To doubt it or to ignore it is to leave patients, like one said in our survey, "gloomy, depressed, unsatisfied." Healthcare practitioners are encouraged to understand this burden of OIC and to discuss it with patients who are already taking, or about to commence taking, opioids for management of chronic pain.

\section{ACKNOWLEDGEMENTS}

AstraZeneca provided funding for survey development and execution, article processing charges and the open access fee. AstraZeneca also provided funding for manuscript development by Epstein Health. Barbara Menzel, Epstein Health, was invaluable in her assistance concerning data management and manuscript development.

All named authors meet the International Committee of Medical Journal Editors (ICMJE) criteria for authorship for this manuscript, take responsibility for the integrity of the work as a whole, and have given final approval for the version to be published.

Disclosures. Robert S. Epstein and J. Russell Teagarden have no conflicts to report aside from the AstraZeneca support for their involvement with the survey. Ali Cimen is an employee of AstraZeneca. Mark Sostek was employed by AstraZeneca, Gaitherburg, MD, USA, during the time of the survey (current affiliation: Pfizer, Collegeville, PA,USA). Tehseen Salimi was employed by AstraZeneca, Gaitherburg, MD, USA, during the time of the survey (current affiliation: Trevena, Inc, King Of Prussia, PA, USA).

Compliance with Ethics Guidelines. This article does not contain any new studies with human or animal subjects performed by any of the authors.

Data Availability. Data sharing is not applicable to this article as no datasets were generated or analyzed during the current study. 
Open Access. This article is distributed under the terms of the Creative Commons Attribution-NonCommercial 4.0 International License (http://creativecommons.org/licenses/ by-nc/4.0/), which permits any noncommercial use, distribution, and reproduction in any medium, provided you give appropriate credit to the original author(s) and the source, provide a link to the Creative Commons license, and indicate if changes were made.

\section{REFERENCES}

1. Scarry E. The body in pain: the making and unmaking of the world. Oxford: Oxford University Press; 1986.

2. Camilleri M, Drossman DA, Becker G, et al. Emerging treatments in neurogastroenterology: a multidisciplinary working group concensus statement on opioid-induced constipation. Neurogastroenterology. 2014;26:1386-95.

3. Kalso E, Edwards JE, Moore RA, McQuay HJ. Opioid in chronic non-cancer pain: systematic review of efficacy and safety. Pain. 2004;112:372-80.

4. Abramowitz L, Béziaud N, Labreze N, et al. Prevalence and impact of constipation and bowel dysfunction induced by strong opioids: a cross-sectional survey of 520 patient with cancer pain DYONISOS study. J Med Econ. 2013;16:1423-33.

5. Bell TJ, Panchal SJ, Miaskowski C, et al. The prevalence, severity and impact of opioid-induced bowel dysfunction: results of a US and European Patient Survey (PROBE 1). Pain Med. 2009;10:35-42.
6. Coyne KS, LoCasale RJ, Datto CJ, et al. Opioid-induced constipation in patient with chronic noncancer pain in the USA, Canada, Germany, and the UK: descriptive analysis of baseline patient-reported outcomes and retrospective chart review. Clin Econ Outcome Res. 2014;6:269-81.

7. Coyne KS, Currie BM, Holmes WC, Crawley JA. Assessment of a stool symptom screener and understanding the opioid-induced constipation symptom experience. Patient. 2015;8:317-27.

8. Bell TJ, Annunziata K, Leslie JB. Opioid-induced constipation negatively impacts pain management, productivity, and health-related quality of life: findings from the National Health and Wellness Survey. J Opioid Manag. 2009;5:137-44.

9. Kwong WJ, Diels J, Kavanagh S. Costs of gastrointestinal events after outpatient opioid treatment for non-cancer pain. Ann Pharmacother. 2010;44:630-40.

10. Epstein RS, Cimen A, Benenson $\mathrm{H}$, et al. Patient preferences for change in symptoms associated with opioid-induced constipation. Adv Ther. 2014;31:1263-71.

11. LoCasale RJ, Datto C, Wilson H, Yeomans K, Coyne KS. The burden of opioid-induced constipation: discordance between patient and health care provider reports. J Manag Care Spec Pharm. 2016;22(3):236-45.

12. Whitman CB, Reid MW, Arnold C, et al. Balancing opioid-induced gastrointestinal side effects with pain management: insights from the online community. J Opioid Manag. 2015;11:383-91.

13. Rauck RL, Hong KJ, North J. Opioid-induced constipation survey in patients with chronic noncancer pain. Pain Pract. 2016; Mar 15 [Epub ahead of print]. 